\title{
Reinstating the roles and places for productive growing in cities
}

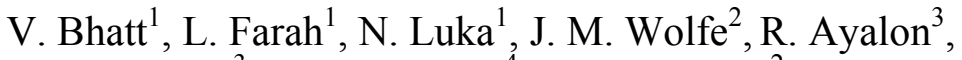 \\ I. Hautecoeur ${ }^{3}$, J. Rabinowicz ${ }^{4}$ \& J. Lebedeva ${ }^{2}$ \\ ${ }^{1}$ School of Architecture, McGill University, Montréal, Canada \\ ${ }^{2}$ School of Urban Planning, McGill University, Montréal, Canada \\ ${ }^{3}$ Alternatives, Montréal, Canada \\ ${ }^{4}$ Santropol Roulant, Montréal, Canada
}

\begin{abstract}
Under ideal circumstances, sustainability, food security, nutrition, public health and environmental quality would be interlinked, for they are vital for the wellbeing of cities. Yet, over the course of the 20th century, cheap fossil-fuel energy, the forces of globalisation, and broader socio-cultural patterns have delocalised food production. Cities are now where the majority of humanity lives, and if they are to be sustainable, it is important to bring productive planting back into urban and peri-urban areas through citizen participation. In addition to reaping the benefits of local food production and engagement with the everyday natural processes that sustain life, productive growing in cities will help reduce their global 'ecological footprint' - made especially large by importing food from faraway places. In the summer of 2007, with the help of volunteers, the authors of this paper created a containerized garden, or the Edible Campus project, on the grounds of McGill University in which sustainability, food security, and environmental quality were linked through innovative urban design to produce food in a challenging urban setting.

Keywords: productive cities, local food production, design, urban environment, Montréal, edible landscapes.
\end{abstract}

\section{Introduction}

Cities are pivotal in reducing global warming; according to the Federation of Canadian Municipalities [1], up to half of Canada's greenhouse gas (GHG) 
emissions (350 million tonnes in 2006) are under the control or influence of municipal governments; hence, in the context of urban environmental degradation and increasing food insecurity - both in quality and quantity greening cities can play an important role. Yet local authorities alone cannot green cities. Their resources are limited and any added responsibility will increase their operating and recurring expenses, resulting in higher taxes, not welcome by citizens. To overcome this impasse, which demands innovative design solutions and concerted social action, our team is working to valorise the greening of the city by fostering participatory cultivating in cities, or making edible landscapes.

When the notion of growing food in urban areas is raised, immediate reactions from professionals, such as architects and planners is to question the availability of land: it is argued that there is not enough space in cities for building, let alone room for growing food. The shortage of adequate community garden plots in cities such as Montréal is also symptomatic of this traditional mindset - one which the Edible Campus project hopes to break.

\section{Project context}

Montréal gives its name to three distinct geographical delimitations: i) an island measuring $500 \mathrm{~km} 2$ bordered by two rivers, ii) an agglomeration of 16 cities including the City of Montréal, which had a 2006 population of 1.85 million, and iii) the municipality of Montréal that is mainly on the island and partly on other smaller adjoining islands. The city of Montréal [2] has an area of $366.4 \mathrm{~km}^{2}$, comprising 19 boroughs (arrondissements) with a population of 620693 in 2006.

\subsection{Food insecurity and disability in Montréal}

In Québec, children represent 38\% of foodbank clients. Furthermore, more than $50 \%$ of families who frequent foodbanks have children. In Montréal, the province's largest city, one citizen in six is affected by food insecurity, and it is mainly the poor, the young and those who are in age to be parents who frequent food banks. This is not a new situation; in 1998, it was estimated that $21 \%$ of those 15 years or older faced to food insecurity in the region of Montréal [3]. In studies related to food security, an often-overlooked subgroup is the disabled population. While data are not readily available for Montréal, recent studies of Toronto by Lister [4] revealed that $48 \%$ of foodbank clients are disabled. Social isolation and food insecurity too often afflict those who have problems with physical mobility. It is vital to address the needs of this largely invisible group.

\subsection{Montréal's public parks, community gardens, and collective gardens}

There are 19 large parks in the Montréal agglomeration in addition to the numerous local parks to be found in every neighbourhood. Nine of the 19 large parks are 'nature parks' covering 1358 ha, as well as four major regional parks and six large city parks, which together cover 3000 ha [5]. Montréal also has a 
long history of community based urban gardening facilitated by the local government since the early 1970 s. In 2002 , there were some 8200 allotments in 97 community gardens and about 30 collective gardens across the city (the former being where people work on small parcels of land individually, the latter involving individuals working together on a single large plot for mutual benefit). Compared to parks, community gardens take up very little space; in 1975, the total area used for community gardens measured 12.7 ha and served 6400 families, Reid and Pedneault [6]. Neither the total number of allotments nor community garden areas, now totalling 12.65 ha, have increased significantly since then. The increased number of gardens was in fact because of municipal mergers. Although community gardens represent a very small portion of urban open space, their impact is noteworthy, for they meet the needs of many citizens and contribute to their food basket - a major reason for their popularity.
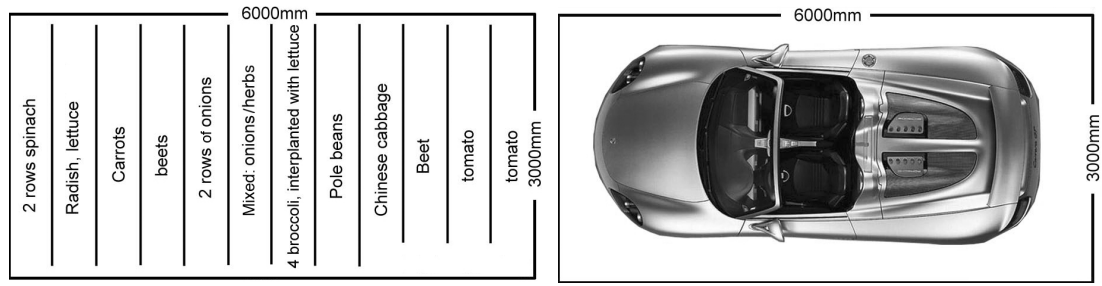

Figure 1: A Montréal community garden plot, which measures $6 \mathrm{~m}$ by $3 \mathrm{~m}$, is the size of a standard parking space.

Demand for gardening plots in Montréal is on the rise; in some neighbourhoods prospective clients must wait two to three years for an allotment garden to become available (Bhatt and Kongshaug [7]). At the same time, soil studies done in 2007 revealed that some of the community gardens located on brownfield sites are contaminated. For safety reasons, the city has opted to ban food growing on these sites, although gardeners are permitted to cultivate decorative plants and flowers. This has further increased pressure on other gardens. Given the high demand and limited supply of space, there is a dire need for innovative and creative strategies to activate sites for urban gardens in Montréal, and for ordinary citizens to be given opportunities to participate in gardening for pleasure, health, and for the yield of edible produce. This is the context in which the Edible Campus project was conceived.

\subsection{The Ville-Marie borough and the edible campus site}

Montréal's downtown Ville-Marie borough had a 2006 population of 78876 [3]. As a municipal unit, the borough maintains 129 public green spaces and 12 community gardens [8]. The two largest of these gardens have recently been closed due to soil contamination - an unfortunate necessity, as they contained more than one-quarter of the borough's available gardening plots. The 10 other community gardens can accommodate only 340 families who wish to grow food. 
Among the borough's many public spaces is the Mont-Royal Park, designed by Frederick Law Olmsted. Sandwiched between it and the downtown core is McGill University's compact downtown campus (figure 2). Consequently, the campus is heavily frequented in the summer months by office workers and local residents, acting as an extension of the large park into the heart of the city. This was the site chosen in 2007 for the Edible Campus initiative.

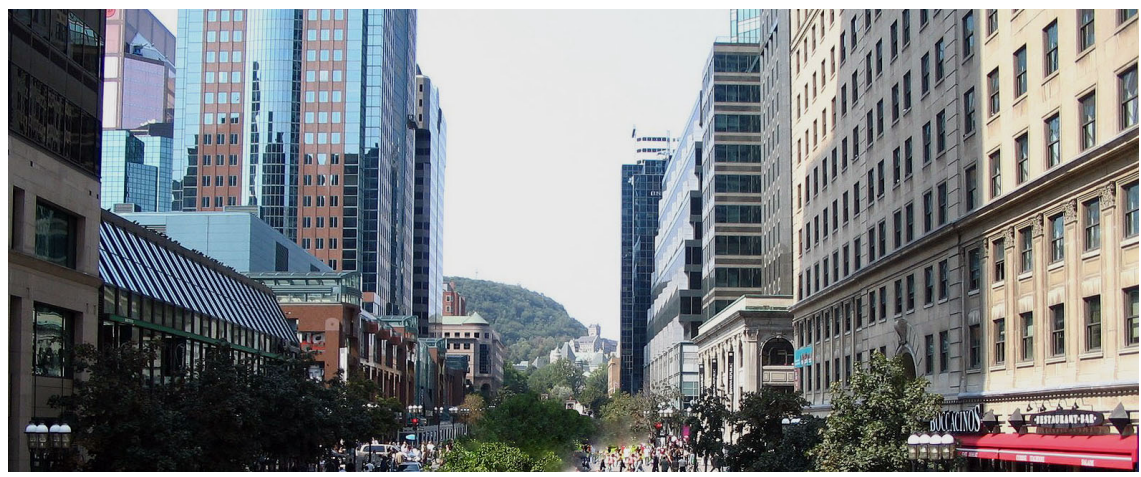

Figure 2: McGill campus (centre), a threshold between the city and the Mont-Royal Park in the background.

The Edible Campus is an action-research project inserted in Ville-Marie. It showcases ways to weave productive planting into urban spaces without diminishing their utility or functionality. A team of researchers from Alternatives and Santropol Roulant (two leading NGOs) and the Minimum Cost Housing Group of McGill University's School of Architecture collaborated to incorporate productive growing in a largely mineralised nook of the campus that is nonetheless has a prominent public location on the University's downtown campus. A $110 \mathrm{~m}^{2}$ container garden was developed - a unique initiative involving citizens, in the creation of a green, edible community space. It also demonstrates how productive planting can be inserted into urban spaces without diminishing their utility or functionality, while exploring strategies for increasing food production by exploiting underutilised and neglected urban spaces such as utility corridors, rooftops, balconies, and terraces.

Remarkably, the garden is maintained by a community of volunteers. More importantly, during the growing season, this garden meets one-third of the needs of fresh organic produce of Santropol Roulant's meals-on-wheels program that serves 100 Montréalers per day, making it a model of a complete urban food cycle.

\section{Linking citizens, communities and institutions}

The Edible Campus is the product of a true community-university partnership. Working independently, none of the partners could achieve what is being done; 


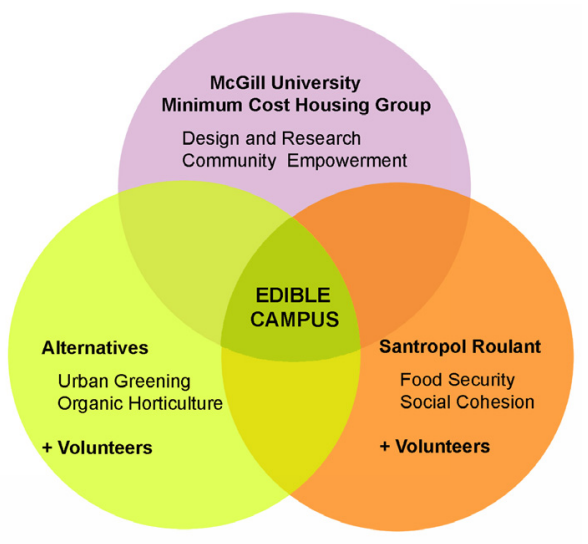

Figure 3: Edible Campus partnership diagram.

acting in concert as a synergistic team has ensured the success of the project. As shown in figure 3 , the project involves three main actors:

- Alternatives, a Canadian NGO working in the field of development. Alternative's Rooftop Gardens Project team [09] is dedicated to the greening of cities. Its aim is to encourage the physical activity of youth, support their interest in organic food, and to involve the infirm and elderly. In addition to these three groups, the team is linked with the volunteers who either live in the neighbourhood or who are students at McGill and other local universities. An electronic mailing list is maintained by Alternatives to inform people about the garden's activities and to welcome new participants.

- $\quad$ The Minimum Cost Housing Group [10], a research and teaching unit of McGill University's School of Architecture. Since 2003, it has been focusing on integrating productive planning in cities on permanent basis through its international "Making the Edible Landscape" action-research project.

- Santropol Roulant [11], an NGO based in Montréal, focuses on food security and inter-generational social connectivity. Its mission is 'to use food as a vehicle to break social and economic isolation between generations and to strengthen and nourish' local communities through a meals-on-wheels and other programs.

The university alone could not have realized this project for several reasons. The university's researchers could design the garden and the campus has available space, but the academic calendar - with its long summer break - and the growing season in Montréal do not match. Most students leave during summer months (the ideal time for growing) and return only in the fall. Similarly, local NGOs have their strengths and limitations. They are wellconnected with local communities and have strong outreach programs, but they lack space for growing food. Yet their non-profit and voluntary mode of operation makes them ideally suited to manage the cultivation, animation and distribution of the harvest. The three partners together developed strategies for 
exploiting this underutilised and neglected concrete space on the campus, an experiment that can serve as a model for many other sites in Montréal and elsewhere.

\subsection{The Edible Campus and social sustainability}

As a social space, the Edible Campus succeeds in bringing together students, seniors, NGOs, and the less fortunate in society to produce a whole greater than the sum of its parts. Socially, it mobilises resources to alleviate the plight of mobility-challenged isolated citizens. Environmentally, it produces quality organic food and helps in making city space biologically productive. Aesthetically, it makes non-descript or hostile urban spaces rich for all the senses, which in turn triggers a continuous interaction of the modular garden with its instigators, volunteers, passers-by, and their surroundings. The Edible Campus, which is a participative garden, might be seen as a fresh manifestation of the Habermas concept of 'communicative action' and the activation of civic space through everyday community activity. The Edible Campus, located on a formerly dull concrete path between two university buildings, is in effect a junction of aesthetics, the productive greening of architecture, and public space or what can be termed 'street democracy'. It engages, involves, and includes the citizenry to consider aspects as mundane as the design, composition and orientation of the containers. This mutual decision-making on the shape, functionality, aesthetics, and utility of city space is ultimately empowering. In short, the Edible Campus brings together individuals from all walks of life, inviting them to participate in caring for the garden and its output; the results include an enriched sense of duty, civic responsibility, and pleasure borne of pride in a site that belongs at once to nobody and everybody. Several aspects bear more detailed discussion.

\subsubsection{Inclusiveness}

Notions of inclusiveness, bottom-up cooperation, synergy and civic communion, all of which are pivotal to the conceptualisation of the Edible Campus, illustrate the intention of making this project a 'grass-roots' event - both figuratively and literally - focusing on the collective aggregation of individual tastes, views, opinions, and energies around this locus of interaction. Anecdotal evidence and interviews with volunteers and NGO members who participate in the activity attest to the multiple impacts (civic, social, educational and personal) that the Edible Campus initiative has had on rethinking urban space and its functions.

\subsubsection{Active community participation}

This bottom-up seasonal initiative involves volunteers who are actively engaged in running the Edible Campus. Community volunteers are involved in every step of gardening, as well as related social-outreach programs. The participatory process includes having volunteers help set up the garden in the spring, as well as watering, weeding and maintaining it, and of course harvesting the produce (figure 4) and delivering it. They are also involved in dismantling the garden for winter storage. 


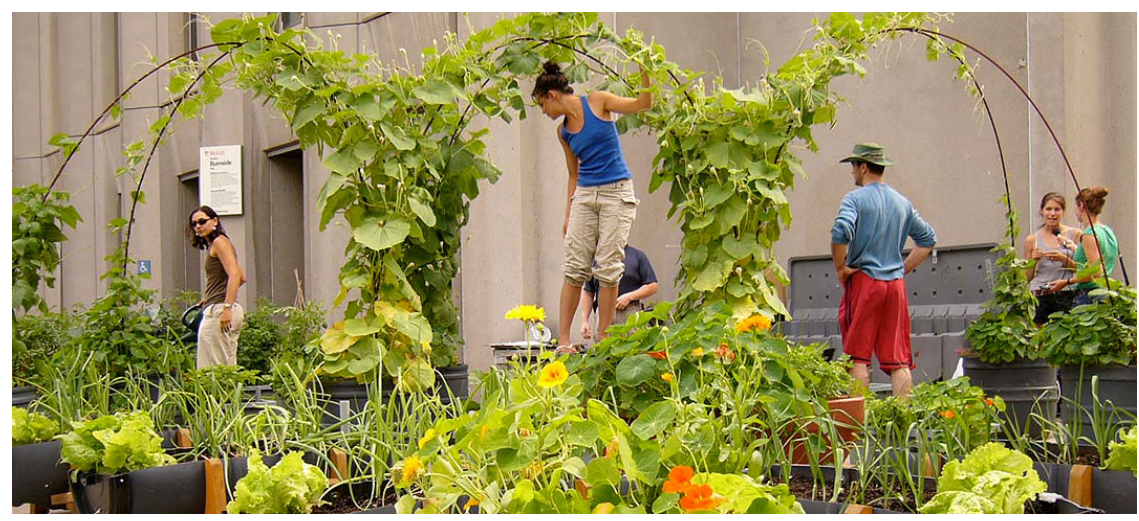

Figure 4: Volunteer participation in food harvesting.

\subsubsection{Social inclusion}

Diverse community members surround the Edible Campus, including the McGill University community, volunteers, NGO actors, and visitors, as depicted in figure 5. The very mixed McGill community mainly comprises students, academics, and staff. Interaction happens on several levels, from simply passing through the site or engaging in conversations that are inspired through curiosity, to cooperation in maintaining the plants or attending events like the harvest festival taking place within the garden. Of particular importance is that the Edible Campus has emerged as a platform for intergenerational exchange and dialogue and social mix.

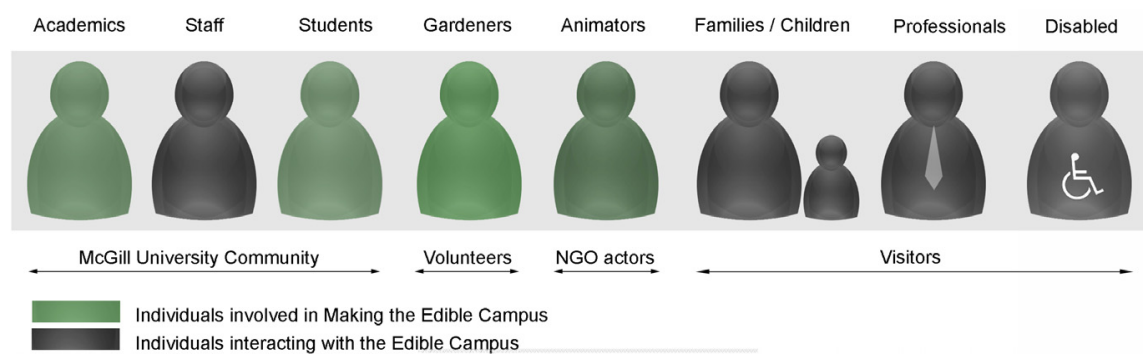

Figure 5: Individuals and groups involved with the Edible Campus.

\subsubsection{Education and demonstration}

The Edible Campus was conceptualised as a democratic exercise in multi-level participation but also as a teaching and learning project. Through its inaugural season, it welcomed organised groups of children and youth, interested professionals and NGOs, as well as students of architecture, urban design, and environment studies. For instance, workshops were organised to give children opportunities to learn about the food cycle, edible plants, and the intricacies of growing food. In the process, the children also contributed to the garden's maintenance (figure 6). 


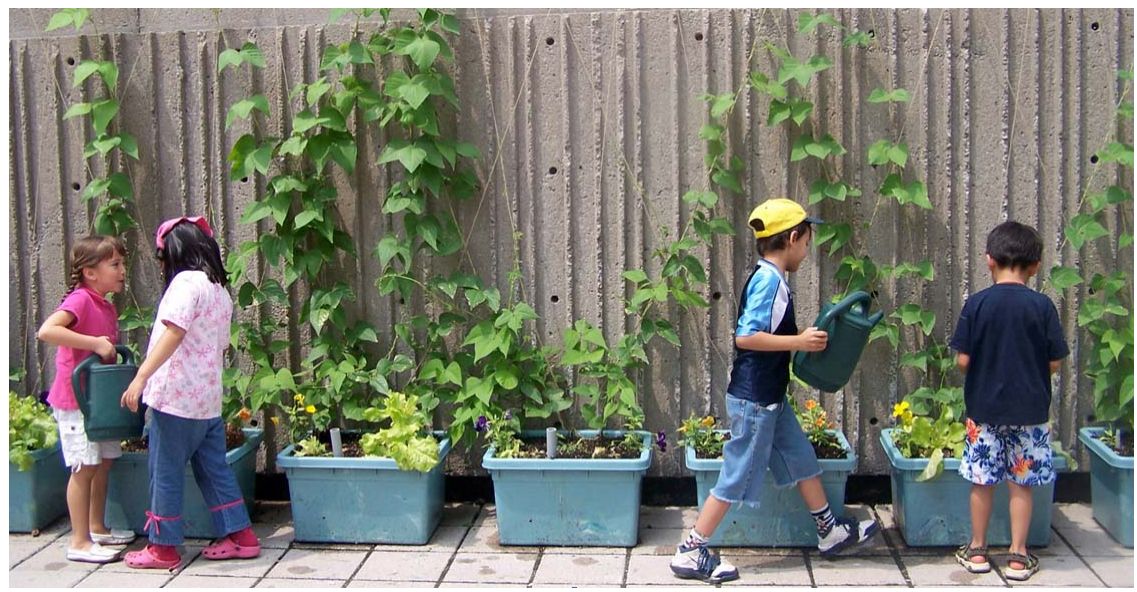

Figure 6: Children learning by doing at the Edible Campus site.

As a design prototype situated at the heart of a world-renowned university with strong programs in architecture, urban design, urban planning, law, and public health, the Edible Campus is well placed to raise awareness of the links between urban design and productive planting among future leaders in many professional domains. Academic programs document and analyse the experimental garden while workshops led by partner NGOs present low-cost urban greening methods to both adults and children.

\subsubsection{Sharing proceeds with vulnerable citizens}

The harvest of the Edible Campus is taken to the kitchens of the Santropol Roulant restaurant (one of the NGO partners in the project), where it is processed and delivered to elderly and mobility-impaired clients through the restaurant's meals-on-wheels program; this helps to reduce social and economic isolation. Its integrated food cycle is literally built through community outreach.

\subsection{Benefits of productive growing in cities: popular perceptions}

The garden has been met with very positive responses from the general public, as revealed through a survey of a random sample of people in its vicinity in late Summer 2007 by Lebedeva [12]. Among the general comments made about the project, respondents noted several advantages: the fact that it is local and sustainable, enhancing self-sufficiency and food security; its beauty; its potential as an affordable source of fresh, organic food; an activity that it is good for the community and for the environment; and its role in helping to raise awareness about environmental issues. In total, $92 \%$ of the respondents felt that the garden should be a permanent feature on the McGill campus, and all but one agreed that similar such food gardens should be introduced elsewhere in cities, such as vacant lots, public parks, and hospital grounds. 


\section{Conclusion}

The sustainability of local economies and particular cities in the $21^{\text {st }}$ century will be defined in large part by how well they respond to the challenges of food security, nutrition, public health, environmental quality, and climate change, especially as energy costs increase dramatically. The Montréal Edible Campus project suggests one small way for major post-industrial cities to 'relocalise' at least part of their food production. This project was achieved not only by design; it was done with the help of community actors, in the process strengthening community links within the central Montréal context. Its productive use of underutilised open space on McGill University's downtown campus was more than the transformation of a blank concrete slate into a dynamic living space, for it created opportunities for people of various social backgrounds in Montréal to come together. As a partnership between grassroots NGOs and public institutions, the project has already proven to be an evocative medium for public education about the benefits of local food production and engagement with the everyday natural processes that sustain life. The project is now continuing on an expanded basis, and it is hoped that its transformative potential will soon spread beyond the institutional context.

\section{References}

[1] Federation of Canadian Municipalities, Clean air and climate change, http://www.fcm.ca/english/View.asp?mp=467\&x=708

[2] Ville de Montréal, Montréal en statistiques, http://www.ville.montreal. qc.ca/

[3] Comité Famille de la CRÉ de Montréal, Regard sur les familles montréalaises: faits saillants, Comité Famille de la CRÉ de Montréal: Montréal, 2007, http://cremontreal.qc.ca/

[4] Lister, N.-M., Placing food. Food-Alphabet City No. 12, ed. J. Knechtel, MIT Press: Cambridge MA, pp. 148-185, 2008.

[5] Conseil régional de développement de l'île de Montréal, Diagnostic environnemental de l'île de Montréal, CRDÎM: Montréal, 2007, http://cremontreal.qc.ca/

[6] Reid, D. and Pedneault, A., Montréal's community gardening program, Ville de Montréal: Montréal, 2006, http://www.ville.montreal.qc.ca/

[7] Bhatt, V., \& Kongshaug, R. (eds.), Making the edible landscape: a study of urban agriculture in Montréal, School of Architecture, McGill University: Montréal, 2005, http://www.mcgill.ca/mchg/pastproject/el/

[8] Ville de Montréal, Ville-Marie: Jardins communautaires, Ville de Montréal: Montréal, 2008, http://www.ville.montreal.qc.ca/

[9] Alternatives, The Rooftop Garden Project, Montréal, http://www. rooftopgardens.ca/

[10] McGill University, Minimum Cost Housing Group, Montréal, http://www. mcgill.ca/mchg/ 
84 The Sustainable City V

[11] Santropol Roulant, La popote intergénérationelle / Nourishing our community, Montréal, www.santropolroulant.org/2006/E-home.htm

[12] Lebedeva, J., Climate change adaptation and mitigation through urban agriculture: a Montréal case study, unpublished graduate supervised research project, school of urban planning, McGill University: Montréal, 2008, http://www.mcgill.ca/urbanplanning/research/studentprojects/ 